\section{Where do you start with utilizing your team?}

\section{Paul A. Eynon}

The journey from 'Saturday student' to fully fledged new graduate veterinary surgeon will see us play an important, if somewhat unconscious, role in the practices we visit. We will go from making cups of tea and wiping off consultation tables, cleaning kennels and accompanying veterinary surgeons out on their calls to practising our skills and testing our knowledge during our clinical extramural studies (EMS), arriving at our end goal - opening the consultation room door and calling in our first client with their pet. Without realizing it, we have been part of a team of people for a very long time, a team who have all played their part in fostering our growth, teaching us some of the softer skills and showing us what their role is in the team. But how often do we step back and acknowledge how much we have gained and indeed, starting out in a new role as part of that team, just how much we can give back?

We will consider the importance of the 'little I' in team and the roles around us, how we can use their expertise and support to enable a smoother transition from student to new graduate veterinary surgeon. Traditionally, we might have looked at those members of the team within the 'bricks and mortar' of the practice, however, veterinary practice has changed, diversified and the teams have also grown.

Stakeholders in our immediate and wider team, in no particular order of importance and in a non-exhaustive list, might include:
Nursing staff
Reception staff
Veterinary colleagues
Practice manager
Year-mates
Employers/seniors
Cleaners
YOU
Clients
University lecturers
Volunteers/school students/EMS students
Delivery staff
Family and friends
Pharmaceutical representatives
Social media
RCVS/BSAVA/BVA/VDS/Scottish SPCA/RSPCA
External laboratories/referral colleagues.

Highlighting who we might turn to when we need help with a 'tricky' client, who might help us organize the paperwork and directions to that lunchtime housecall, how we could include our year-mates in one another's out-of-hours rota for maximal learning, how to be ourself in the partnership with our clients - being honest about what we know and don't know yet, how to prepare for our first school and EMS students coming to shadow us.

We will discuss some of the anxieties surrounding entering into and being part of a new team, taking on a new role within an existing team and strategies we could employ to help maximize the positive experience that comes from being a team player.

Together we will explore outside the traditional team how we fit in to this 'new' role, how we will support ourselves and realize the support that we are able to offer other members of our team.

\section{KEY LEARNING OBJECTIVES}

- Be able to appreciate the roles of key stakeholders within the 'team'

- Be able to identify opportunities for reciprocal support starting out in practice

- Be able to explore the value you bring to the team as a student progressing to new graduate

\section{MULTIPLE CHOICE QUESTIONS}

1. Who might your experienced colleagues 'turn to' for an update on recent developments in treating conditions?
(A) Reception staff
(B) You
(C) Pharmaceutical representative
(D) Practice manager

2. Which members of your team are most likely to encounter emotionally charged situations first, in the practice?
(A) The delivery driver
(B) EMS student
(C) Reception staff
(D) Your boss

3. Who in your team are you likely to learn the most from during your first month in practice?
(A) Reception staff
(B) Nursing staff
(C) Veterinary colleagues
(D) All of the above 